\title{
Nota Científica \\ Diagnóstico do marketing ambiental de bens e serviços do setor florestal
}

\author{
Erlon Barbosa Valdetaro¹, Mayra Luiza Marques da Silva Binoti ${ }^{1}$, Daniel Brianezi ${ }^{1}$, Laércio Antônio Gonçalves Jacovine ${ }^{1}$
}

${ }^{1}$ Universidade Federal de Viçosa, Av. Peter Henry Rolfs s/n, CEP 36571-000, Viçosa, MG, Brasil

"Autor correspondente:

erlon.valdetaro@ufv.br

Termos para indexação:

Marketing ambiental

Setor florestal

Apelo ambiental

Index terms:

Marketing environment

Forest sector

Environmental appeal

Histórico do artigo:

Recebido em 05/04/2011

Aprovado em 28/02/2012

Publicado em 29/06/2012

doi: $10.4336 / 2012 . p f b .32 .70 .105$
Resumo - Foram realizadas coletas e análises em propagandas e campanhas publicitárias de empresas de produtos e serviços florestais em nove revistas e 91 websites do setor, buscando propagandas e ações de marketing que tivessem algum tipo de apelo ambiental, tais como termos ambientais, símbolo com apelo ambiental, selo de certificação e imagem com apelo ambiental. O “termo ambiental” está presente em 85,9\% das 157 propagandas pertencentes a diversos segmentos florestais. O setor florestal tem adotado o marketing ambiental como ferramenta de adequação ao mercado, com o intuito de atender uma sociedade cada vez mais crítica e consciente das problemáticas ambientais atuais.

\section{Diagnosis of environmental marketing goods and services in the forestry sector}

\begin{abstract}
It was collected and subsequent analysed advertisements and advertising campaigns for companies of forest products and services in nine magazines and 91websites of the forest sector, seeking for advertising and marketing actions that had some kind of environmental appeal as environmental terms, symbols with environmental appeal, certification seal and image with environmental appeal. The "environmental term" is present in $85,9 \%$ of 157 forest advertisements from different segments. The forestry sector has embraced the environmental marketing as a tool to adapt to the market, to meet an increasingly more critical and aware of current environmental issues.
\end{abstract}

\section{Introdução}

O setor florestal brasileiro tem uma importante participação no desenvolvimento social e econômico do país. Em 2007, esse setor contribuiu com 3,4\% do Produto Interno Bruto (PIB), 5,6\% do total de exportações, $18,5 \%$ do superávit da balança comercial, gerando aproximadamente, $9,0 \%$ do total de empregos diretos e indiretos (Sociedade Brasileira de Silvicultura, 2008). Nesse contexto, destaca-se o setor de papelão ondulado, que conta com 80 empresas, 103 unidades industriais instaladas, e gera 14.602 empregos diretos, de acordo com o Anuário da Associação Brasileira de Papelão Ondulado
(Anuário... 2006). Segundo a Sociedade Brasileira de Silvicultura (2008), o parque industrial brasileiro, voltado à produção de madeira serrada (pranchas, vigas, caibros, tábuas, etc.), dispõe de, aproximadamente, 10.000 unidades fabris, predominando aquelas de pequeno porte. Já o setor de celulose e papel no Brasil é composto por 220 empresas, localizadas em 17 estados.

As empresas pertencentes ao setor florestal, principalmente aquelas que buscam diferenciação dos seus produtos e/ou serviços, têm investido cada vez mais em ações de marketing,

Para Oliveira \& Waissman (2002), a estratégia de marketing está centrada em um conjunto de informações 
a respeito do mercado, dos clientes e da concorrência. A comunicação é considerada como sendo uma informação tratada de modo estratégico, e a inteligência aplicada aos usos que serão dados a essas informações é que determinará a garantia de torná-las vantagens competitivas que agreguem valor à marca.

A diferenciação ambiental de produtos e serviços é denominada marketing ambiental, que tem como sinônimos os termos marketing verde, marketing ecológico e ecomarketing. Esse tipo de marketing baseiase em ações planejadas que geram e facilitam trocas direcionadas à satisfação das necessidades e desejos humanos, e que ocorrem com o mínimo de impacto sobre o meio ambiente (Gonzaga, 2005; Guimarães, 2006; Baisch, 2008; Brandão, 2009).

De acordo com Motta \& Oliveira (2007), o marketing ecológico é mais afeito à criação de vantagem competitiva baseada em diferenciação, com ou sem enfoque. Os custos de implantação de suas ações são maiores, assim como o valor ofertado aos consumidores também é maior. Os autores afirmam ainda que a empresa que não se preocupar com a atitude favorável dos consumidores em relação às questões ambientais pode deixar de obter vantagem competitiva.

A indústria, especialmente aquela que exporta grande parte de sua produção, também recebe pressões internacionais sobre os padrões mínimos de manejo ambiental. Na prática, uma indústria que exporta mais de $90 \%$ de sua produção precisa se adequar tanto à legislação vigente no Brasil, quanto às leis e exigências do mercado internacional (Oliveira \& Waismann, 2002).

Um exemplo disso são as denominadas indústrias de baixo carbono. Diante de um cenário internacional em que há exigências cada vez maiores por ações de mitigação da emissão dos gases de efeito estufa (GEE), as indústrias têm adotado modos de produção mais eficientes e ferramentas de compensação de suas emissões, minimizando seus impactos negativos no meio ambiente.

Para Nardelli \& Griffith (2003), a inserção da variável ambiental nos negócios, apesar de recente, sinaliza mudanças no setor florestal. Por várias décadas, a eficiência de uma empresa teve como maior foco seu campo técnico, ou seja, o conjunto de aspectos relativos aos seus insumos, processos e produtos. Hoje, porém, a empresa florestal interage com as diversas demandas das partes interessadas, incluindo a opinião pública e as tendências de mercado. Entre os vários agentes envolvidos estão o governo, as organizações nãogovernamentais - ONGs, as comunidades vizinhas, os trabalhadores, os consumidores, os fornecedores, os competidores, os pesquisadores e os investidores. Juntos, formam o campo organizacional do setor florestal. É este campo que irá perceber e interpretar os impactos resultantes das atividades do setor, estabelecendo os limites aceitáveis para sua realização.

As empresas do setor florestal promovem as ações de marketing com apelo ambiental para divulgar suas ações sustentáveis. Para subsidiar o conhecimento dessas ações foram realizadas coletas e análises em propagandas e campanhas publicitárias de empresas de produtos e serviços florestais durante um período de 60 dias, em março e abril de 2010. Foram coletados 157 anúncios publicitários diferentes em nove revistas da área florestal/ambiental e, posteriormente, checou-se estes anúncios nos respectivos websites das empresas anunciantes. Ao todo, 91 websites foram pesquisados.

Os anúncios coletados pertenciam aos seguintes segmentos florestais: máquinas para colheita ou transporte florestal; construção (casas de madeira); consultoria florestal; energia (carvão vegetal, resíduos florestais); fertilizantes e defensivos florestais; madeira serrada; painéis; papel e celulose; pisos; tratamento da madeira e viveiro florestal. A análise consistiu na identificação e na verificação da credibilidade das estratégias utilizadas para estimular o consumo dos produtos e serviços dessas estratégias.

Dos 157 anúncios, foram encontradas 85 propagandas com algum tipo de apelo ambiental como "termo ambiental", com pelo menos um termo com indicação do comportamento sustentável da empresa; "símbolo com apelo ambiental", que é um desenho com algum significado de atitude ambientalmente correto, porém não é um selo de certificação; "imagem com apelo ambiental", que é uma foto ou ilustração que não tem qualquer relação com o produto ou serviço, mas enfatiza o apelo ambiental da propaganda; e "selo de certificação", que é um símbolo de um selo de certificação florestal ou ambiental.

As 85 propagandas de empresas de produtos e serviços florestais com algum tipo de apelo ambiental corresponderam a $54,1 \%$ do total de anúncios amostrados e distribuíram-se nos seguintes segmentos: painéis $(25,9 \%)$; madeira serrada $(25,9 \%)$; máquinas para colheita ou transporte florestal $(12,9 \%)$; energia $(10,6 \%)$; papel e celulose $(5,9 \%)$; pisos $(4,7 \%)$; consultoria 
florestal (4,7\%); viveiro florestal (3,5\%); construção $(2,4 \%)$; fertilizantes e defensivos florestais $(2,4 \%)$; e tratamento da madeira $(1,2 \%)$.

Foi observado maior percentual de anúncios com apelo ambiental ligados ao segmento de painéis, possivelmente pelo alto consumo no mercado nacional. Além disso, a Associação Brasileira da Indústria de Painéis de Madeira (2010) afirma que fatores estruturais como aumento real da renda, ampliação do emprego, maior oferta de crédito, crescimento do PIB e o ambiente favorável da construção civil poderão aumentar a demanda por móveis e, por extensão, o consumo de painéis de madeira industrializada. Deste modo, o segmento é impulsionado a investir em publicidade nas revistas e websites mais procurados por seu público-alvo.

$\mathrm{O}$ apelo ambiental mais utilizado nas propagandas foi do tipo "termo ambiental", presente em $85,9 \%$ das propagandas analisadas, seguido por "imagem com apelo ambiental" (41,2\%), "selo de certificação" $(30,6 \%)$ e "símbolo com apelo" (12,9\%).

Os 11 termos com apelo ambiental mais frequentes encontrados nas propagandas foram: "ecossistema"; "verde"; "biodiversidade"; "aquecimento global"; "desperdício"; "limpo"; "reciclagem (reciclar)"; "redução de impacto"; "IBAMA"; "ecológico"; "renovável"; "protege floresta nativa"; "manejo"; "natureza"; "responsabilidade ambiental"; "ambiental"; "respeito"; "sustentável (sustentabilidade)"; "preservação"; e "meio ambiente" (Figura 1).
Foi possível identificar que segmentos do setor florestal se preocupam com as questões ambientais e de sustentabilidade, e isso se comprova através da utilização do apelo ambiental em aproximadamente $54 \%$ das ações de marketing e publicidade encontradas neste estudo.

Nota-se que algumas propagandas que utilizam termos ambientais possuem frases como "preservamos o meio ambiente", "respeitando a natureza", "produzimos de forma ecológica", sem qualquer comprovação ou informação de como realizam tais práticas.

As propagandas que utilizam frases como "preservamos a floresta nativa" baseiam-se na idéia de que ao consumirem madeira oriunda de florestas plantadas (reflorestamentos), preservam as florestas naturais.

A questão do aquecimento global é abordada no sentido de que, ao se plantar árvores ou usar florestas manejadas, os efeitos climáticos decorrentes do desmatamento de florestas nativas são amenizados. Desta forma, a empresa se compromete a neutralizar suas emissões de GEE, isentando, de certa maneira, o cliente desta responsabilidade com o meio ambiente. Ainda que esta seja uma prática incipiente no mercado de produtos florestais brasileiros, projeta-se um crescimento desta ação, devido à problemática do aquecimento global.

O IBAMA (Instituto Brasileiro de Meio Ambiente) é apresentado em alguns anúncios como referência para escolha de madeira, normas de tratamentos e como certificador dos produtos.

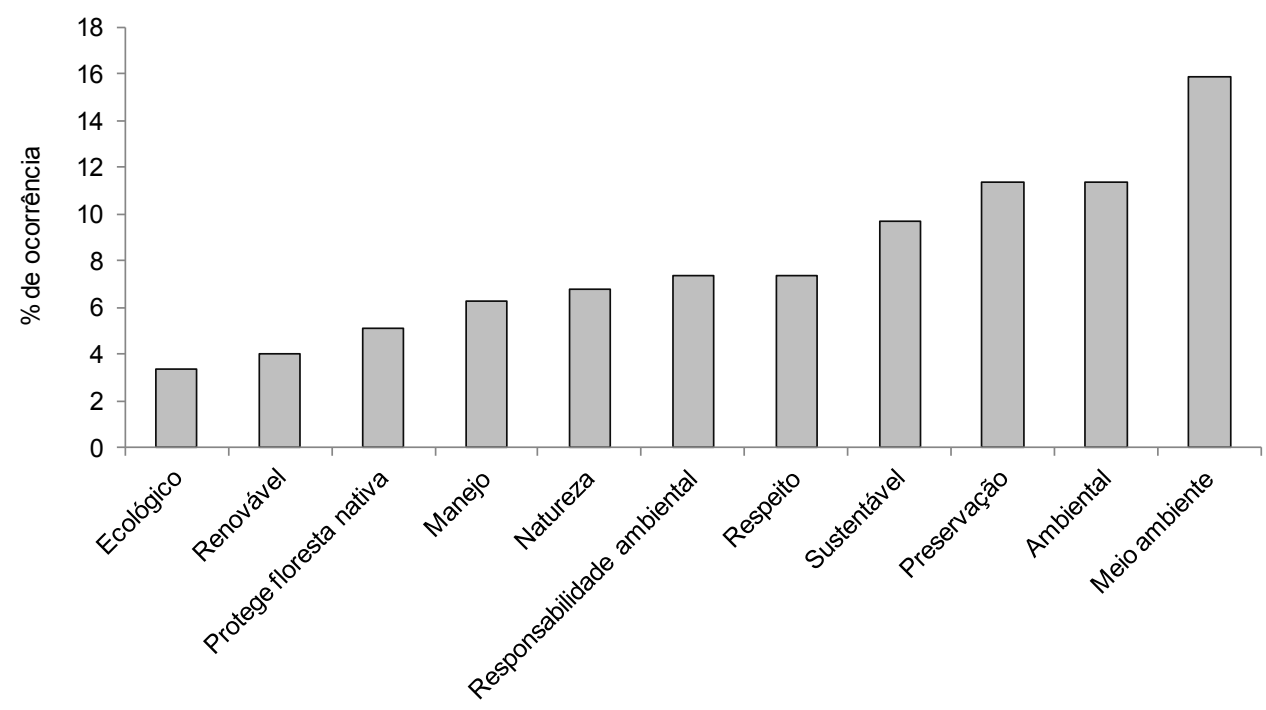

Figura 1. Termos com apelo ambiental de maior ocorrência (\%) nas propagandas dos produtos e serviços florestais. 
Os símbolos com apelo ambiental encontrados nas propagandas ressaltam a ideia defendida pela empresa nas suas práticas ambientais, mas sem representar qualquer garantia de que essas práticas são realmente aplicadas e/ou certificadas na empresa.

Os selos de certificação presentes nas propagandas pertencem ao FSC (Forest Stewardship Council) e ao CERFLOR (Programa Brasileiro de Certificação Florestal). Estes selos atestam que a floresta manejada e/ ou o processo produtivo atendem às normas estabelecidas pelos respectivos programas de certificação.

Estes selos representam uma garantia ao consumidor das práticas ambientais da empresa, dando credibilidade à propaganda e à empresa. As empresas que apresentam as certificações nos seus anúncios são dos segmentos de painéis $(53,8 \%)$, madeira serrada $(26,9 \%)$, papel e celulose $(11,5 \%)$ e pisos $(7,7 \%)$, conforme Figura 2.

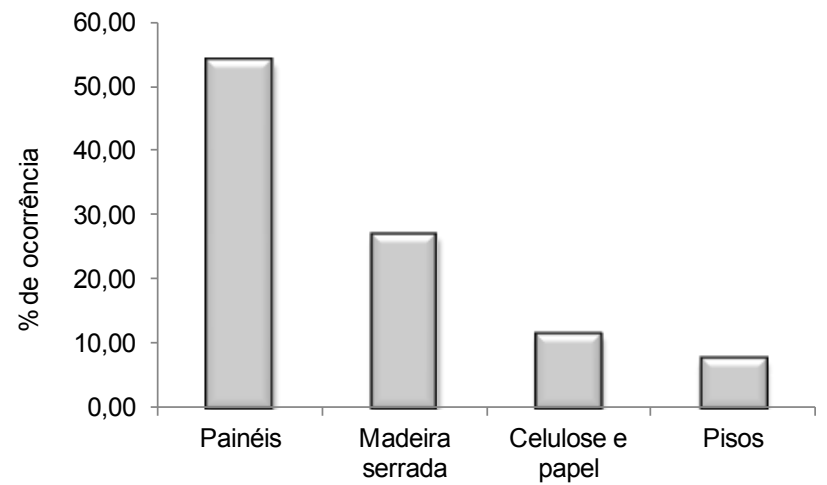

Figura 2. Proporção dos segmentos florestais que apresentam selos de certificação em suas propagandas.

As empresas que têm maior volume de produtos voltados para o mercado de exportação sofrem maior pressão do mercado internacional, por isto buscam com mais frequência algum tipo de certificação ambiental/ florestal para o seu produto. De acordo com Oliveira \& Waismann (2002), estas empresas visam responder as pressões internacionais sobre os padrões mínimos de manejo ambiental, respeitando e adaptando-se às leis e aos requisitos do exigente mercado internacional.

O setor de celulose e papel é o principal segmento exportador da área florestal, correspondendo a 89,8\% do total. Já as exportações de painéis de madeira industrializada representaram $1,1 \%$ da exportação total em 2009 e o volume exportado de madeira serrada obteve incremento de 8,4\% no período, totalizando US\$ 154 milhões (Anuário..., 2011).
As propagandas analisadas evidenciam que o setor de segmentos de painéis é o que mais apresenta algum tipo de certificação em seus anúncios, o que mostra a preocupação do setor em comprovar as suas ações ambientais e sustentáveis.

Apesar disso, o mercado consumidor do segmento de celulose e papel não abrange diretamente os leitores/ consumidores das revistas da área florestal, pois a celulose (matéria-prima) é exportada para outras indústrias, produtoras de papel. Em contrapartida o segmento de painéis, apesar de contribuir menos para o volume total de exportações, possui um maior número de empresas de produção e comercialização desses produtos permitindo que o consumidor (leitor da revista) tenha a possibilidade de comprar o produto final (painéis e derivados) a partir do anúncio em revista, justificando o valor de 53,8\% de anúncios de certificação encontrados no segmento de painéis contra apenas $11,5 \%$ do setor de celulose.

É notório que o setor florestal, bem como outros setores, adote nas estratégias de marketing de seus produtos ou serviços a prática do marketing ambiental, visando se adequar ao mercado, agregar valor ao seu produto, buscar um diferencial em relação à concorrência e responder a uma sociedade cada vez mais crítica e consciente das problemáticas ambientais atuais. Diante da dimensão do setor florestal brasileiro, é salutar a realização de um diagnóstico do uso de marketing ambiental dentro de cada segmento do setor, que aponte as suas especificidades e subsidie decisões estratégicas futuras relacionadas às ações publicitárias.

\section{Referências}

ANUÁRIO Estatístico da ABRAF 2011: ano base 2010. Brasília, DF, 2011. Disponível em: $<$ http://www.abraflor.org.br/estatisticas.asp $>$. Acesso em: 19 set. 2011.

ANUÁRIO Estatístico ABPO 2007: ano base 2006. São Paulo, 2006.

BAISCH, L. B. Marketing verde e o consumo consciente: um estudo sobre o apelo ecológico de dois produtos. 2008. 115 f. Dissertação(Mestrado em Administração) - Pontifícia Universidade Católica do Rio de Janeiro, Rio de Janeiro, RJ.

BRANDÃO, M. R. de M. Análise da interação dos stakeholders na adoção de estratégias de marketing verde: um estudo em empresa moveleira. 2009. 85 f. Dissertação (Mestrado em Ciências em Engenharia de Produção) - Universidade Federal do Rio Grande do Norte, Natal, 2009.

GONZAGA, C.A. M. Marketing verde de produtos florestais: teoria e prática. Floresta, Curitiba, v. 35, n. 2, p. 353-368, 2005. 
GUIMARÃES, A. F. Marketing verde e a propaganda ecológica: uma análise da estrutura da comunicação em anúncios impressos. 2006. 191 f. Tese (Doutorado em Administração) - Universidade de São Paulo, SP.

MOTTA, S. L. S.; OLIVEIRA, B. O marketing ecológico como vantagem competitiva. Revista de Gestão USP, São Paulo, v. 14, n. 2, 2007.

NARDELLI, A. M. B.; GRIFFITH, J. J. Modelo teórico para compreensão do ambientalismo empresarial do setor florestal brasileiro. Revista Árvore, Viçosa, MG, v. 27, n. 6, 2003.
OLIVEIRA, J. A. P.; WAISMAN, V. Integrando ação e comunicação para uma estratégia de marketing ambiental: o caso Aracruz celulose. REAd: Revista Eletrônica de Administração, Porto Alegre, v. 8, n. 6, nov./dez. 2002. Edição especial, n. 30.

SOCIEDADE BRASILEIRA DE SILVICULTURA. Fatos e números do Brasil florestal. São Paulo, 2008. Disponível em: $<$ http://www.sbs.org.br/fatosenumerosdobrasilflorestal.pdf $>$. Acesso em: 21 set 2011. 
